\title{
PARQUE LINEAR DO SAPÉ: O DESCOMPASSO ENTRE CONSCIÊNCIA E AÇÃO
}

\author{
Eduardo Pimentel Pizarro ${ }^{1}$ e Suzana Sanches Lino² \\ 1 Arquiteto e urbanista pela Faculdade de Arquitetura e Urbanismo da Universidade de São Paulo. \\ Mestrando em Tecnologia da Arquitetura pela Fauusp. Email: eduardo.pizarro@usp.br \\ 2 Arquiteta e urbanista pela Faculdade de Arquitetura e Urbanismo da Universidade Braz Cubas de \\ Mogi das Cruzes. Email:suzanasancheslino@gmail.com
}

\begin{abstract}
Resumo
A partir do Programa dos 100 Parques, lançado pela Prefeitura do Município de São Paulo em 2008, é destacada a leitura do projeto e implantação do Parque Linear do Sapé, na Zona Oeste do município. O Estudo de caso suscita reflexões acerca da produção destes parques e sua relação com o homem urbano, observando-se como são inseridos, nos projetos de parques lineares, as questões de ecologia, águas urbanas e processos naturais.
\end{abstract}

Palavras-chave: infraestrutura verde, parque linear, córrego do Sapé, Programa 100 Parques, ecologia urbana, água urbana.

\section{SAPÉ LINEAR PARK: THE GAP BETWEEN AWARENESS AND ACTION}

\begin{abstract}
From the Program of the 100 Parks, launched by the Municipality of Sao Paulo in 2008, is highlighted reading the design and implementation of the Sape's Greenway, in the western zone of the municipality. The case study raises thoughts about the production of these parks and theirs relationship to the urban man, observing how they are inserted in the greenways' projects, issues of ecology, urban water and natural processes.
\end{abstract}

Keywords: green infrastructure, greenway, Sape's stream, 100 Parks Program, urban ecology, urban water. 


\section{INTRODUÇÃO}

Estima-se que, em 2050, $75 \%$ da população global seja urbana1. Atualmente, no Brasil, $84,35 \% 2$ o é. Quando se trata do Município de São Paulo, esta porcentagem atinge $98,94 \% 3$. De fato, as cidades são hoje e, nas próximas décadas, o "palco dos acontecimentos", onde se concentram as atividades econômicas, políticas, sociais, culturais, além das oportunidades e conflitos. Contudo, como estão sendo produzidas, neste panorama, as cidades, em especial as brasileiras? É premente, portanto, a necessidade de pararmos para pensar, discutir, propor e projetar cidade.

Essencial para o debate e desenho de cidade é o seu Sistema de Espaços Livres, a ser encarado como real infraestrutura urbana, uma Infraestrutura Verde. Entretanto, surge outra indagação: onde está a questão ambiental na lógica de construção das cidades brasileiras? Parece ainda ser pertinente o que Michael Hough diz acerca da relação estabelecida entre homem e seu meio (cidade + natureza, ou cidade $x$ natureza), na medida em que "os conceitos humanidade e natureza tem sido entendidos durante muito tempo como problemas separados."4 (HOUGH, 1998, p.09, tradução nossa). E esta deficiente abordagem da questão ambiental urbana faz-se presente nas ideologias e iniciativas públicas, privadas e da população urbana de um modo geral.

Uma das tentativas de inserção da problemática ambiental na escala urbana de maior repercussão dos últimos anos, pela Prefeitura do Município de São Paulo, é o Programa 100 Parques, lançado em 2008. De acordo com o Programa, a intenção seria partir dos 34 parques municipais existentes em 2005 (15 milhões $\mathrm{m}^{2}$ de área protegida), para 60 parques ( 24 milhões $\mathrm{m}^{2}$ ) em 2009, concluindo em 2012, com um total de 100 parques municipais ( 50 milhões $\mathrm{m}^{2}$ )5. Todavia, o saldo atual é de 81 parques implantados no município. Dos 50 parques lineares previstos em 2008, pela campanha

1 BURDETT, Ricky. "City-thinking for City-building” In ROSA, Marcos. "Microplanejamento.

Práticas urbanas criativas". São Paulo, Editora Cultura, 2011.

2 IBGE 2010.

3 IBGE 2010.

$4 \quad$ "Ios conceptos humanidad y la naturaleza se ha entendido durante mucho tiempo como temas separados." (HOUGH, 1998, p.09).

5 Site da Secretaria Municipal do Verde e do Meio-ambiente: www.prefeitura.sp.gov.br/cidade/ secretarias/meio-ambiente/parques/programa_100_parques. 
eleitoral de Kassab, 24 foram concluídos e a previsão é de mais 6 até o fim do ano . Há um déficit, portanto, de 20 parques lineares.

Neste programa municipal destaca-se a concepção de Parques Lineares que, como mecanismos "anti-enchentes", em uma visão significativamente mecanicista. Apesar disso, de acordo com a Secretaria do Verde e Meio Ambiente, os parques lineares "[...] constituem uma nova diretriz infraestrutural, definindo faixas de utilidade pública ao longo dos cursos d'água com o objetivo de implantação de uma infraestrutura verde de recuperação ambiental e lazer." "Nova diretriz"? Só se pensarmos a escala de Brasil, talvez nem assim. Olmsted, nos EUA, já em 1865, experimenta a implantação dos princípios dos parques lineares, por meio da intervenção Strawberry Creek. Além disso, em quê, realmente, reside esta preferência pelos parques lineares, na sua importância ecológica e urbana, ou na facilidade de implantação? Estes parque lineares conformam uma real infraestrutura verde, que manchas ecológicas eles buscam conectar e fortalecer?

Além disso, em que medida este programa contribui, efetivamente, para a cidade, levando-se em conta as esferas ambiental, social e humana, principalmente, nas diversas escalas? Até que ponto esta iniciativa, junto a tantas outras, não passam de uma estratégia que articula, simplesmente, um montante de dados, números e marketing político?

A partir destas provocações propõe-se a leitura de um dos primeiros parques lineares implantados, mas ainda em processo de implantação, segundo esta política, o Parque Linear do Sapé, na Zona Oeste de São Paulo.

\section{PARQUE LINEAR DO SAPÉ}

O Parque Linear do Sapé foi projetado ao longo do córrego de mesmo nome, inserido na bacia do ribeirão do Jaguaré, no Distrito Rio Pequeno, Subprefeitura do Butantã. O parque se estende desde a Rodovia Raposo Tavares, onde nasce o córrego, até a Avenida Escola Politécnica, onde o córrego desemboca no Ribeirão do Jaguaré.

6 Dados da Secretaria Municipal do Verde e Meio Ambiente. 


\section{Revista LABVERDE}
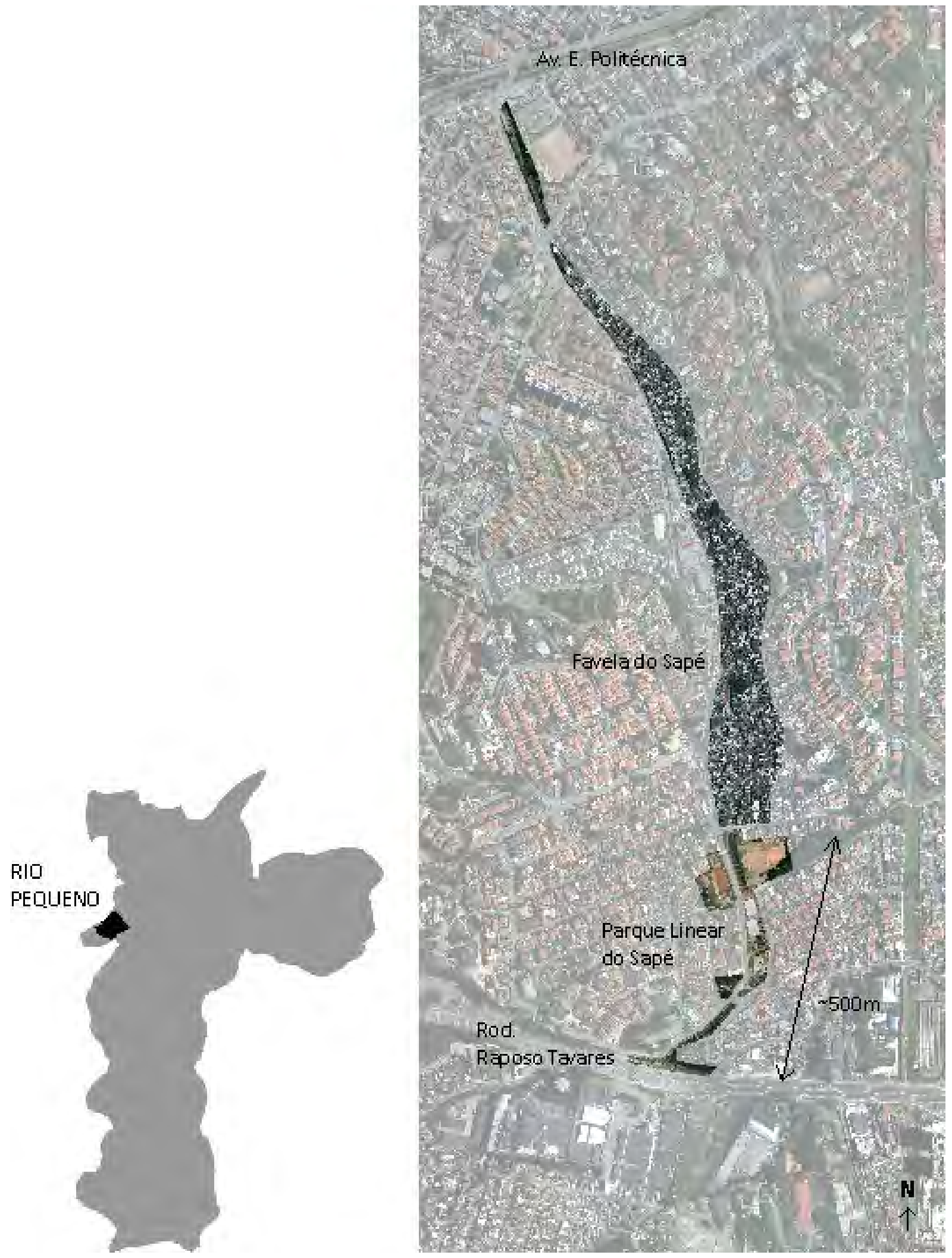

Figuras 01: localização do distrito Rio Pequeno no Município de São Paulo. Figura 02: localização da área total de intervenção do Parque Linear do Sapé. Fonte: base do Google Earth e trabalho gráfico dos autores. 


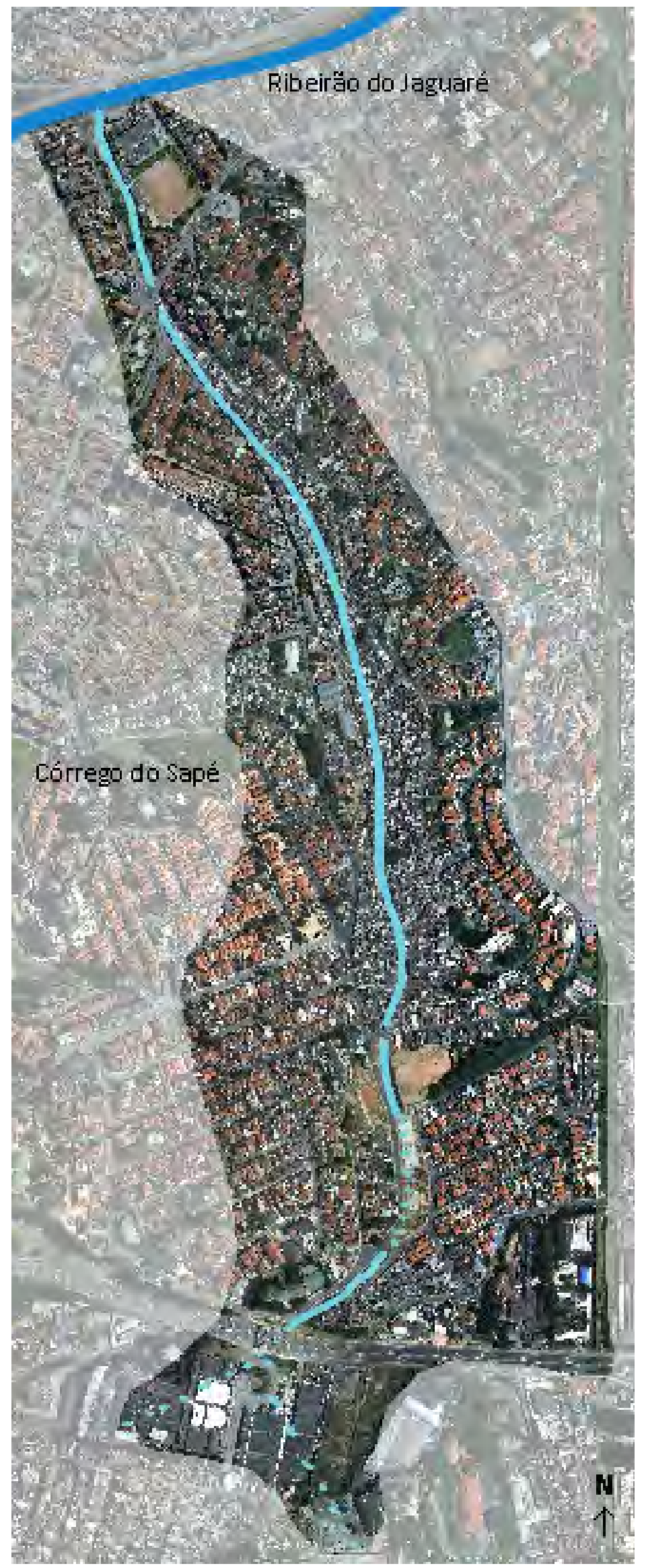

Figura 03: delimitação da Sub-Bacia do Córrego do Sapé, e destaque da rede hídrica. Fonte: base do Google Earth e trabalho gráfico dos autores. 
O parque é viabilizado pela instauração de compensação ambiental. Os novos parques municipais de São Paulo são produzidos a partir de três principais alternativas, com verbas da Secretaria do Verde e Meio Ambiente (SVMA), do Fundurb (Fundo de Desenvolvimento Urbano), ou por meio de Termos de Compensação Ambiental (TAC). A estratégia do TAC é empregada desde 2006, como parte do Programa de Recuperação Ambiental dos Cursos D'água e Fundos de Vale, proposto pelo Plano Diretor Estratégico de 2002. No caso específico do Parque Linear do Sapé, do custo aproximado de 5 milhões (referente ao primeiro trecho), parte foi assumida pela SVMA e o restante por duas empresas imobiliárias que, ao cortarem árvores para construção de um conjunto habitacional no Morumbi, efetivaram esta compensação. Neste ponto, surge a questão: não seria melhor que estas empresas tivessem de fazer uma contrapartida nas proximidades do local de intervenção, no Morumbi, neste caso? Além disso, em que medida esta política de compensação, com construção de parques por parte da iniciativa privada, não contribui para o decréscimo de sua qualidade e aplicação de parâmetros comerciais aos espaços livres públicos?

O Parque Linear do Sapé também está inserido no Programa Córrego Limpo, lançado em 2007 por uma parceria entre Prefeitura do Município de São Paulo e Governo do Estado, por meio da Sabesp (Companhia de Saneamento Básico do Estado de São Paulo). A intenção do projeto é reverter a degradação dos córregos urbanos. Até o final de 2011, foram "despoluídos" 103 córregos e a previsão é de mais 49 até o final do $\mathrm{ano}^{7}$.

O parque, originalmente, tencionava dar um uso a uma área desocupada junto ao trecho inicial do Córrego do Sapé, entre a rodovia e a Rua Calixto Garcia. Posteriormente, junto a outras secretarias municipais, acordou-se a necessidade de estender o parque até a Avenida Escola Politécnica, atravessando uma área favelada, com habitação em áreas de risco, degradação e desvalorização dos recursos hídricos.

A primeira fase de implantação, original, portanto, foi iniciada em 2005 e concluída em 2009, ocupando uma área de $26.240 \mathrm{~m}^{28}$, com uma extensão de aproximadamente $500 \mathrm{~m}^{9}$.

7 Sabesp, Programa Córrego Limpo.

8 Prefeitura de São Paulo.

9 Medição a partir de Google Earth. 
A fase seguinte, em processo de desapropriação e intervenção, intervém na Favela do Sapé, que se estende até a Avenida Escola Politécnica, completando um parque linear com extensão de $2 \mathrm{Km}$, aproximadamente.

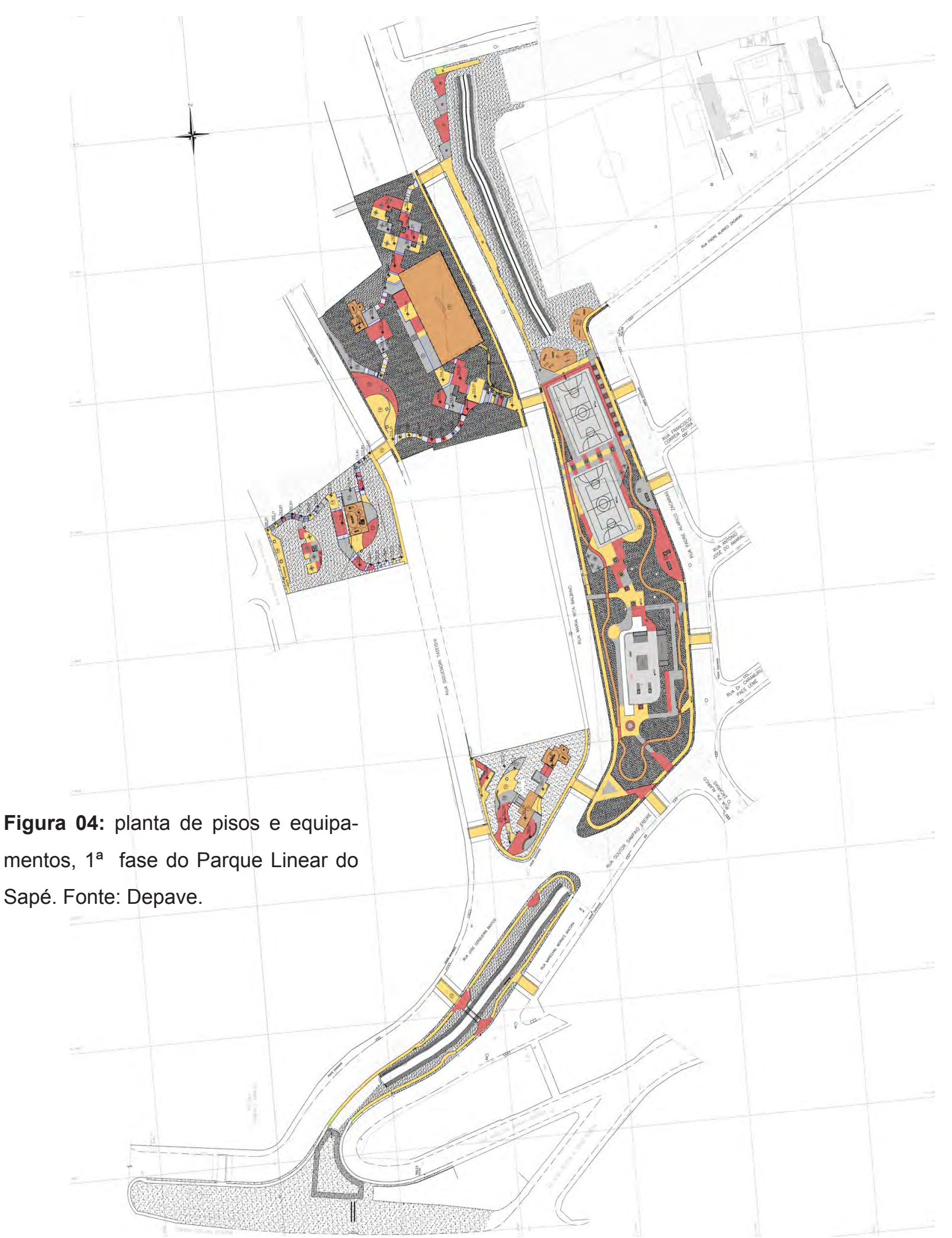




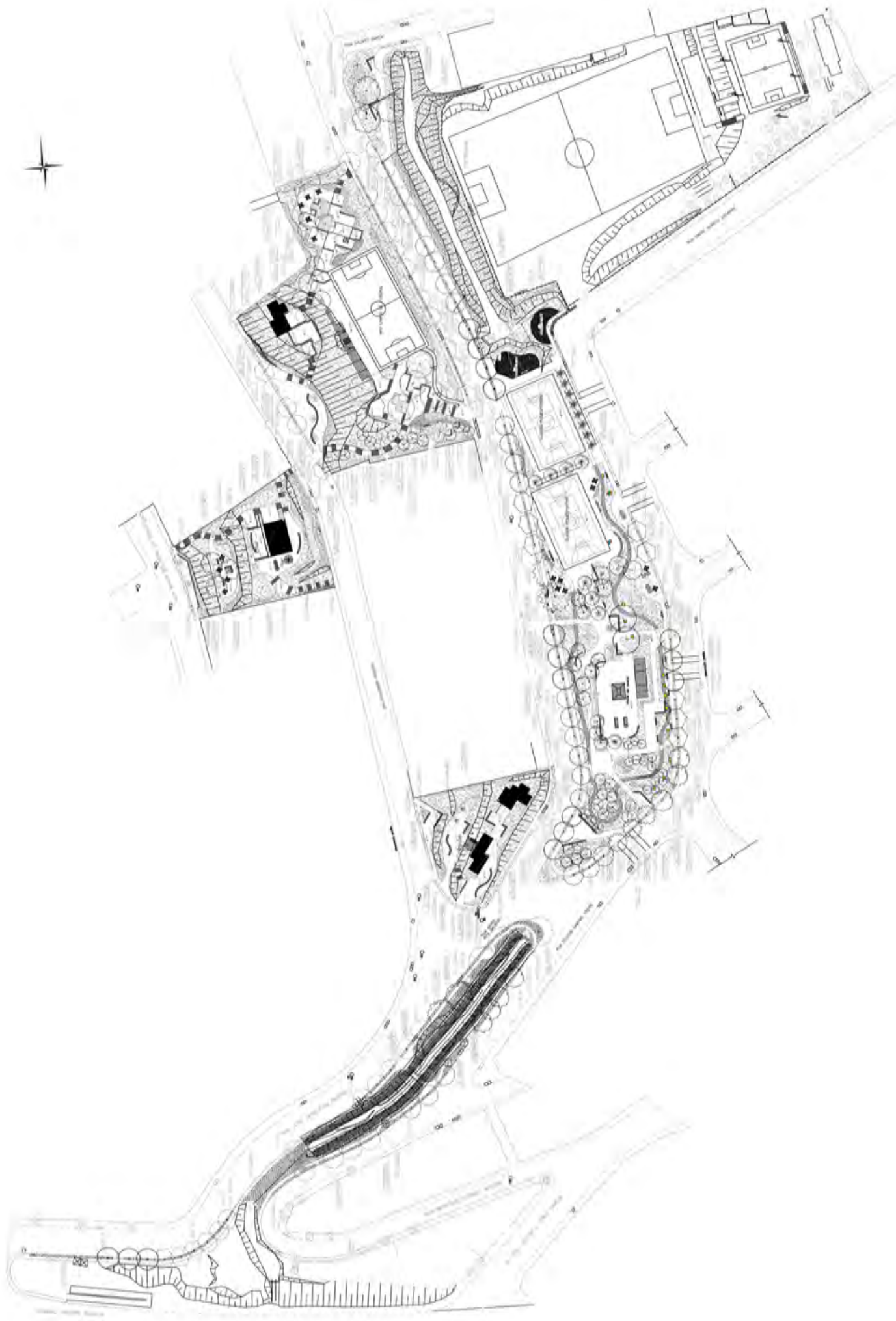

Figura 05: planta de paisagismo, $1^{a}$ fase do Parque Linear do Sapé. Fonte: Depave. 


\section{PROJETO DAS ÁGUAS}

Michael Hough relata que "A forma urbana revela sua história natural e humana, e o ciclo contínuo dos processos naturais"10(HOUGH, 1998, p.18, tradução nossa); Contudo, "O ambiente urbano nos isola dos processos naturais e humanos que sustentam a vida"11 (HOUGH, 1998, p.15, tradução nossa); Por fim, "Grande parte de nossa existência diária passamos em lugares desenhados para encubrir os processos que sustentam a vida, o que contribui, possivelmente mais que qualquer fator, para o empobrecimento sensorial do entorno em que vivemos." ${ }^{12}$ (HOUGH, 1998, p.29, tradução nossa)

As palavras de Hough são vistas, concretamente, na primeira fase do Parque Linear do Sapé, já implantada. O modo com que o projeto se apropria das águas e as relaciona ao meio urbano merece uma discussão.

O projeto manteve expostos os córregos nas extremidades da área. Entretanto, no trecho intermediário do parque, ao invés de levar a água à luz, o projeto instalou "equipamentos de lazer", duas quadras poliesportivas, pista de skate e playground. O rio permanece oculto por mais de $200 \mathrm{~m}$, dificultando a leitura dos processos naturais na cidade. Não seria adequada uma estratégia intermediária, talvez com a realocação de uma quadra poliesportiva e exposição do córrego?

10 "El camino a un lugar revela su historia natural y humana, y el ciclo continuo de los procesos naturales." (HOUGH, 1998, p.18)

11 "El medio ambiente urbano en el aislamento de los procesos naturales y humanos que sustentan la vida" (HOUGH, 1998, p.15)

12 "Gran parte de nuestra existencia cotidiana pasado en lugares destinados a encubrir los procesos que sustentan la vida, lo que contribuye, quizás más que cualquier otro factor, el emprobecimiento del medio ambiente sensorial en el que vivimos." (HOUGH, 1998, p.29) 


\section{Revista LABVERDE}

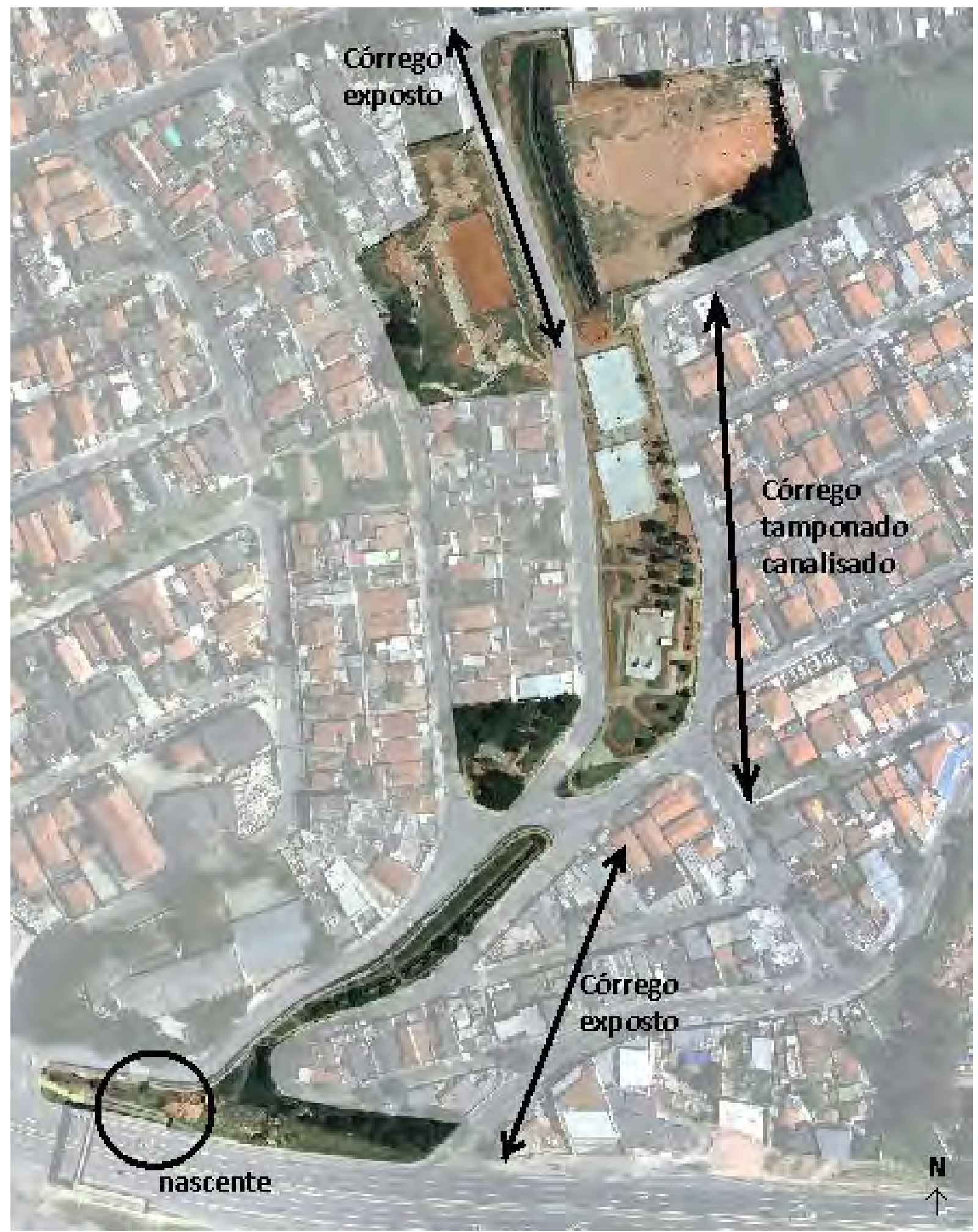

Figura 06: Parque Linear do Sapé implantado ( $1^{\text {a }}$ fase $)$ e sua relação com a água. Fonte: base de Google Earth e trabalho gráfico dos autores. 

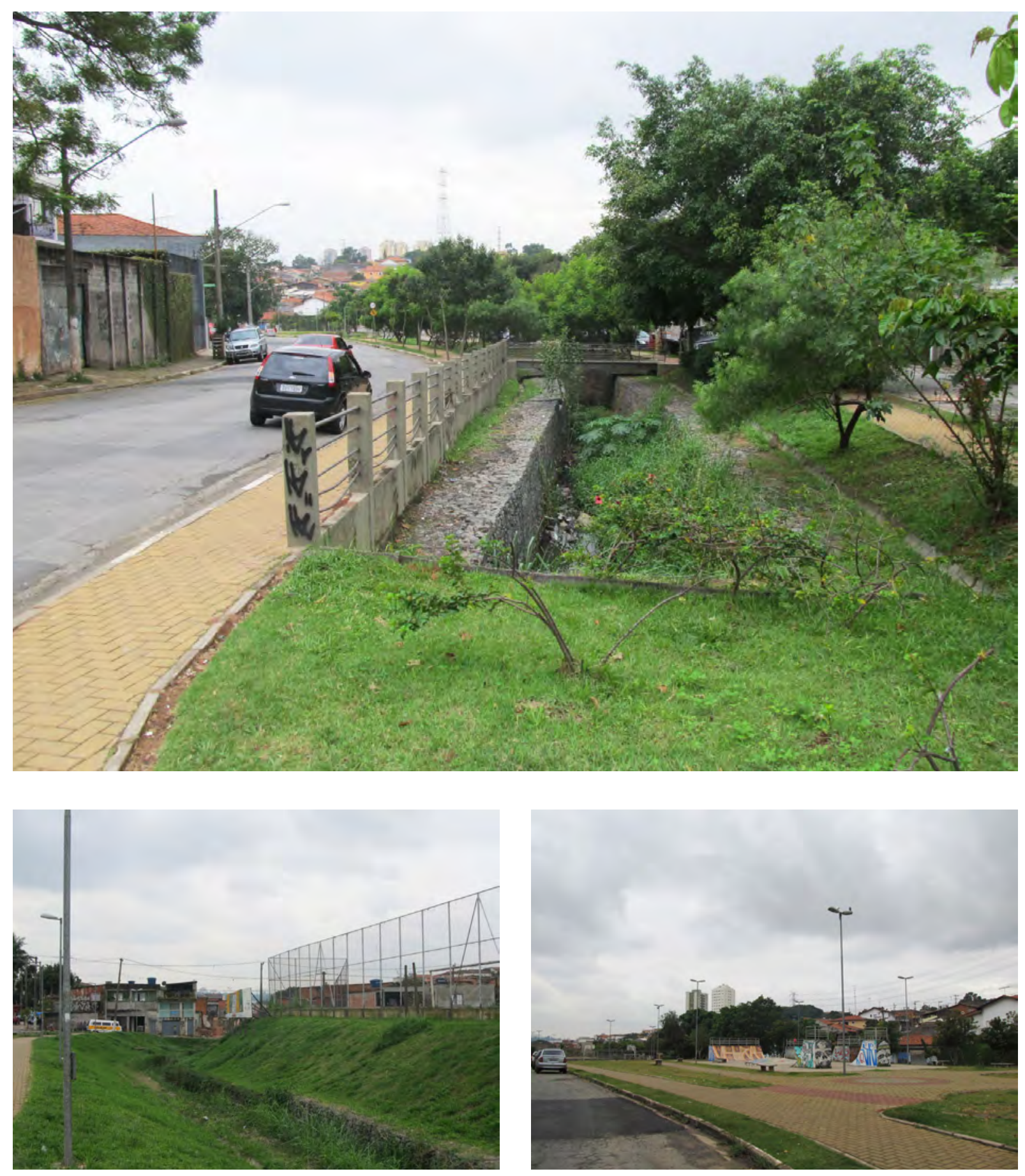

Figuras 07, 08 e 09: sequência de imagens da primeira fase do Parque Linear do Sapé, a jusante do córrego do Sapé. Fonte: visita no dia 15/05/2012.

Não basta delinear, parcialmente, o caminho das águas. Apenas a partir da compreensão do relevo e do caminho das águas e, portanto, das dinâmicas ambientais, é que a população compreenderá, efetivamente o meio em vive. E, uma vez compreendendoo, passará a respeitá-lo e se sentir parte dele. 
Os corpos d'água expostos são delimitados por muros de gabião. Esta alternativa é válida frente às paredes concretadas impermeáveis, na medida em que permitem a troca de fluidos e crescimento de formas vegetais espontâneas. Contudo, seria mais interessante se o córrego pudesse não estar condicionado por estes muros, livre, natural, dinâmico, redesenhando constantemente seus contornos, ao longo do tempo e na oscilação entre períodos de cheia e seca. Mas a alternativa de gabião parece ter sido adotada para conter o processo de erosão, uma vez que as margens são estreitas, o que resultaria em barrancos muito íngremes.

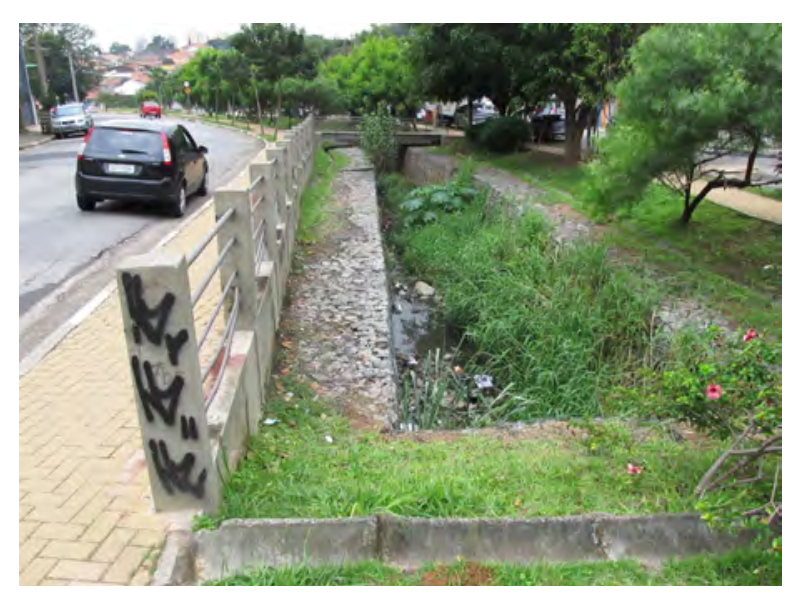

Figuras 10: o rio delineado com gabiões, no Parque Linear do Sapé. Fonte: visita no dia 15/05/2012.

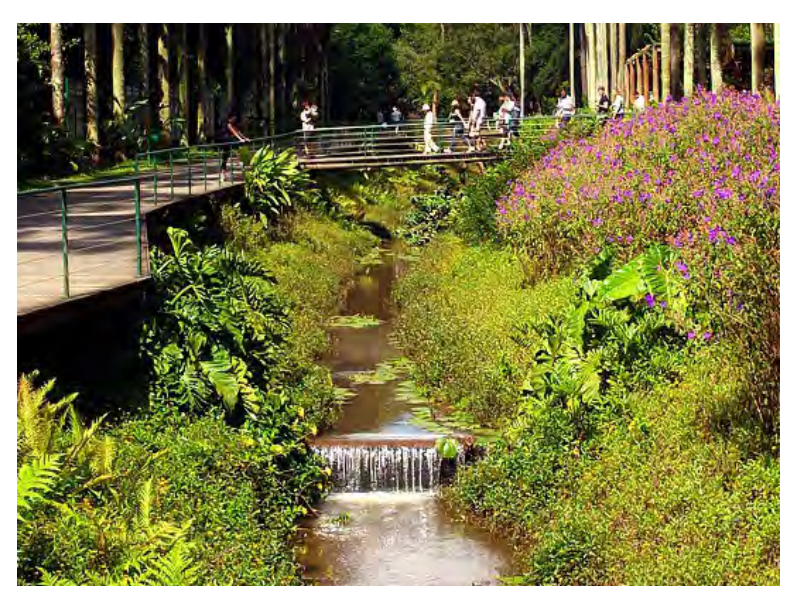

Figura 11: "rio naturalizado" no Jardim Botânico de São Paulo. Fonte: bonsprojetosdepaisagem. blogspot.com.

Apesar de inapreensível, o parque abriga a nascente do córrego, nascente esta que surge a partir de um par de tubos de concreto, trazendo consigo dejetos materiais, uma imagem nada "triunfal" ou emblemática em referência à sua função ecológica. A população permanece, desta forma, em dúvida: de onde vem a água? é água ou é esgoto? 

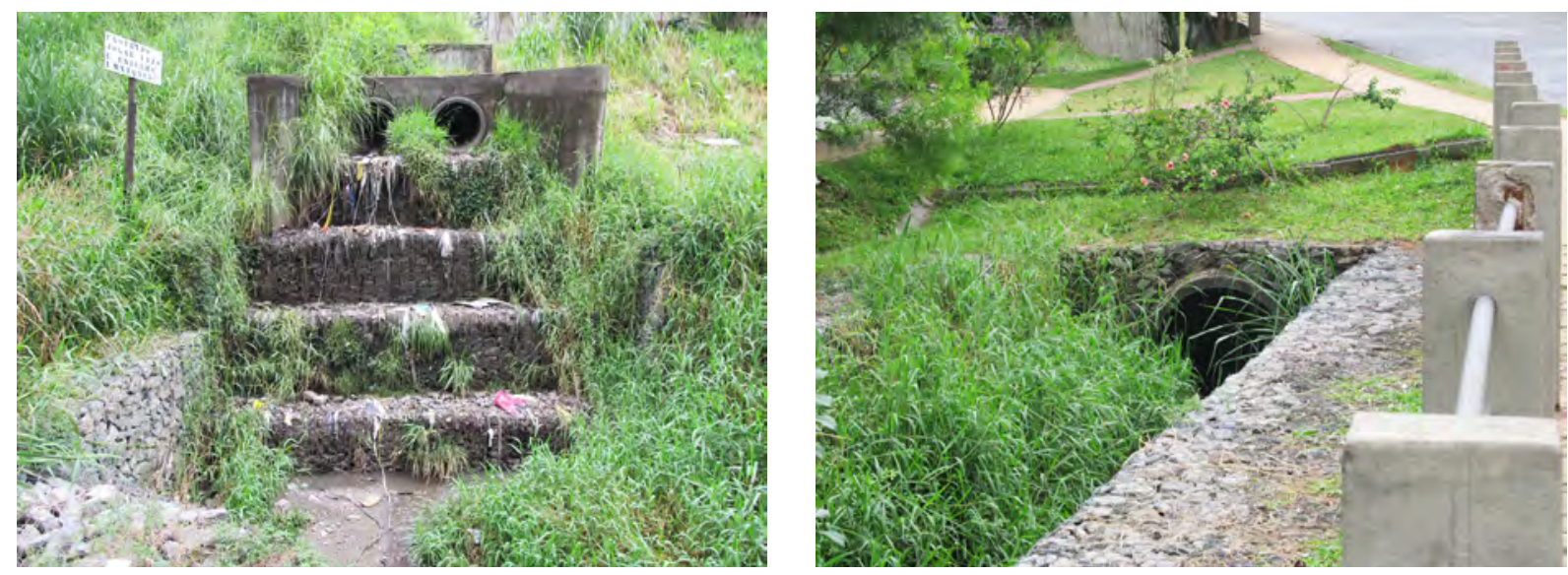

Figuras 12 e 13: as "tubulações" do córrego. Figura 12 com destaque para a "nascente". Fonte: visita no dia 15/05/2012.

Observando-se o córrego, percebe-se, portanto, "a mão pesada do homem", que tentou, de uma certa forma, requalificá-lo. Para a população da favela e do entorno, o rio "está bonito" assim. A maior preocupação destes homens é diminuir o risco de enchentes que invadem as ruas e suas casas, levando consigo o lixo que eles mesmos ali despejaram. Na verdade, a população não se incomodaria se o rio fosse inteiramente tamponado.

A água é ainda encarada como simples máquina urbana, brotando de encanamentos e esvaindo-se por eles. O córrego presta-se ao recebimento direto da água pluvial que, depois de escoar por calçadas e ruas, chega, por encanamentos subterrâneos ou canaletas superficiais, ao córrego, trazendo impurezas. Uma das funções das margens do parque linear, aliás, seria, por meio de diversos estratos vegetais, permitir uma filtragem desta água suja antes de entrar em contato com a água limpa do corpo d'água, a priori.
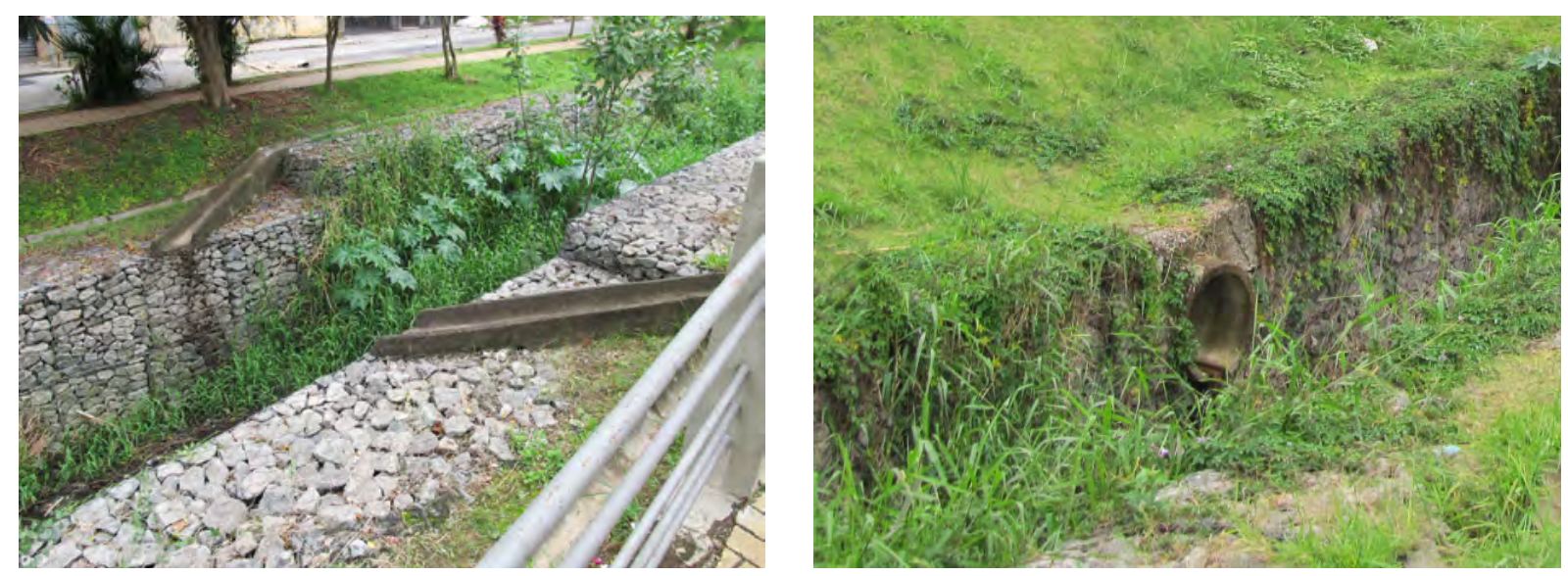

Figuras 14 e 15: águas pluviais descarregadas diretamente no córrego. Fonte: visita no dia 15/05/2012. 
Aliás, a preocupação com a vegetação e sua diversidade é parca, no parque implantado. Grande parte da vegetação é pré-existente, como se torna visível pela comparação das imagens aéreas. As áreas junto aos equipamentos esportivos e à favela do Sapé são desprovidas de qualquer vegetação que não seja rasteira. Mesmo o restante do parque não possui estratos intermediários de vegetação, essenciais para a filtragem das águas.
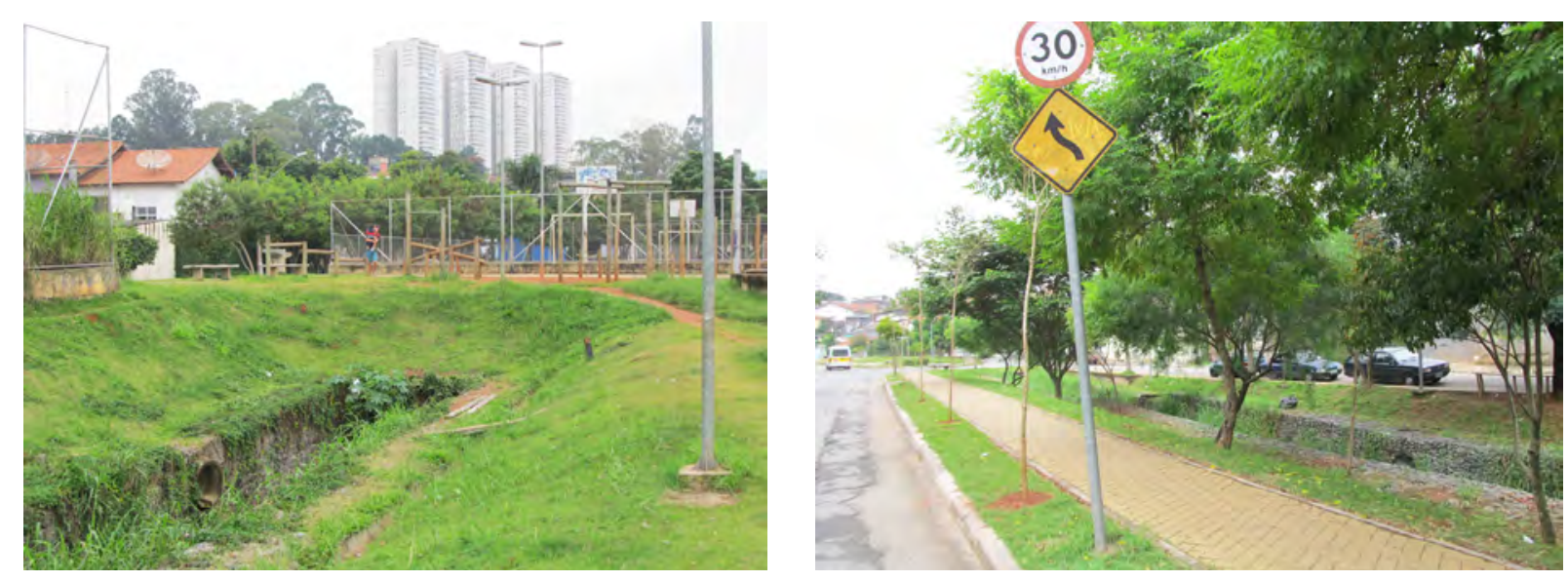

Figura 16: vegetação rasteira e arbórea pré-existente. Figura 17: margens do córrego apenas com gramíneas. Fonte: visita no dia 15/05/2012.

No projeto destes parques lineares, o rio é apenas mais um elemento, secundário. A intervenção não leva a água como dado de projeto.A água não é explorada como elemento urbano, tanto para conscientização ambiental, quanto para o uso recreativo, por exemplo, principalmente na medida em que os pequenos rios estão em processo de despoluição.

\section{LÓGICA DE PROJETO}

Com relação aos materiais empregados no parque linear, qualquer empreendimento privado ou praça no outro extremo da cidade, ou até mesmo em outros estados do país, terá este mesmo piso permeável padrão. É interessante a preocupação com a multiplicação das áreas permeáveis no meio urbano, mas não seria válido buscar alternativas menos impessoais, talvez relacionadas a uma produção local, com cooperativas de moradores? 

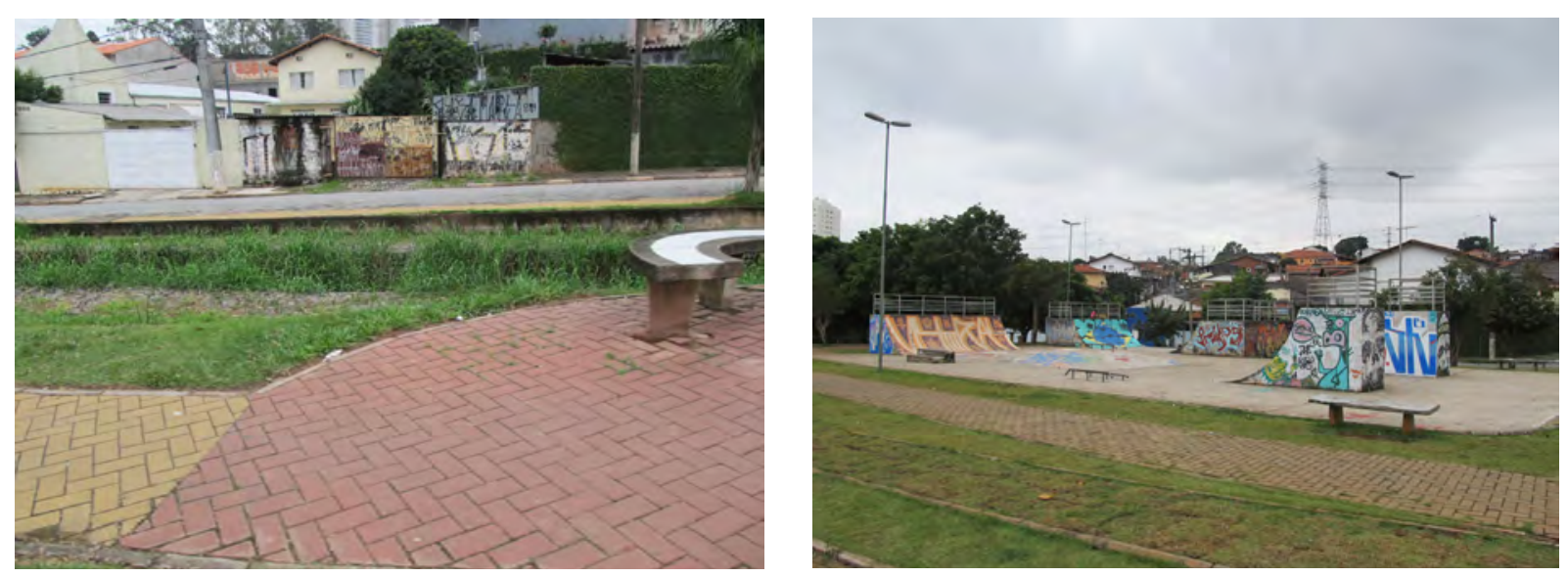

Figuras 18 e 19: materiais, percursos e estado de conservação do parque. Fonte: visita no dia 15/05/2012.

As próprias dimensões dos caminhos são questionáveis. No trecho inicial do parque, a largura do piso não passa de $1 \mathrm{~m}^{13}$, largura inadequada à passagem confortável de mais de um pedestre por um passeio público. No restante do parque as dimensões são suficientes, principalmente pela existência de percursos alternativos. A acessibilidade universal adequadamente projetada, parece não ter sido idealmente implantada.

O estado de conservação e manutenção do parque é bom, sem lixo ou dejetos acumulados, vegetação bem cuidada, equipamentos públicos preservados. Este estado é resultado da intervenção pública na limpeza e manutenção e da relação estabelecida entre o espaço público e seu usuário.

Os parques lineares ao longo de corpos d'água seguem, em verdade, a mesma lógica de qualquer praça pública e até mesmo de qualquer térreo de condomínio residencial fechado. Estes parques são, em essência, um desenho de piso que mescla planos de relvados e peças semipermeáveis coloridas, sobre o qual são dispostos uma série de equipamentos de apreciação, recreação e esportes.

Não há desenho de espaço público. Há desenho de disposição de equipamentos, que se tornam, em si, a função e o fator atrativo do parque. Se não fossem colocados os equipamentos, ou o espaço permaneceria vazio, apenas como espaço de circulação, ou a população buscaria se apropriar dele, ressignificando-o ${ }^{14}$ e dando-o, propriamente, um uso.

13 Medida in loco.

14 Conceito de ressignificação: FRANCO, Fernando de Mello. "Contrários e complementares."

In ROSA, Marcos. Microplanejamento. Práticas urbanas criativas. São Paulo, Editora Cultura, 2011. 
Assim como trata Paola Berenstein Jacques ${ }^{15}$, estamos em um processo de espetacularização da cidade e, especialmente, de seus espaços públicos, pontos estratégicos para que se alcance tal objetivo. A construção destes espaços se faz, portanto, por práticas homogeneizadoras, com criação de cenários e espaços desencarnados.
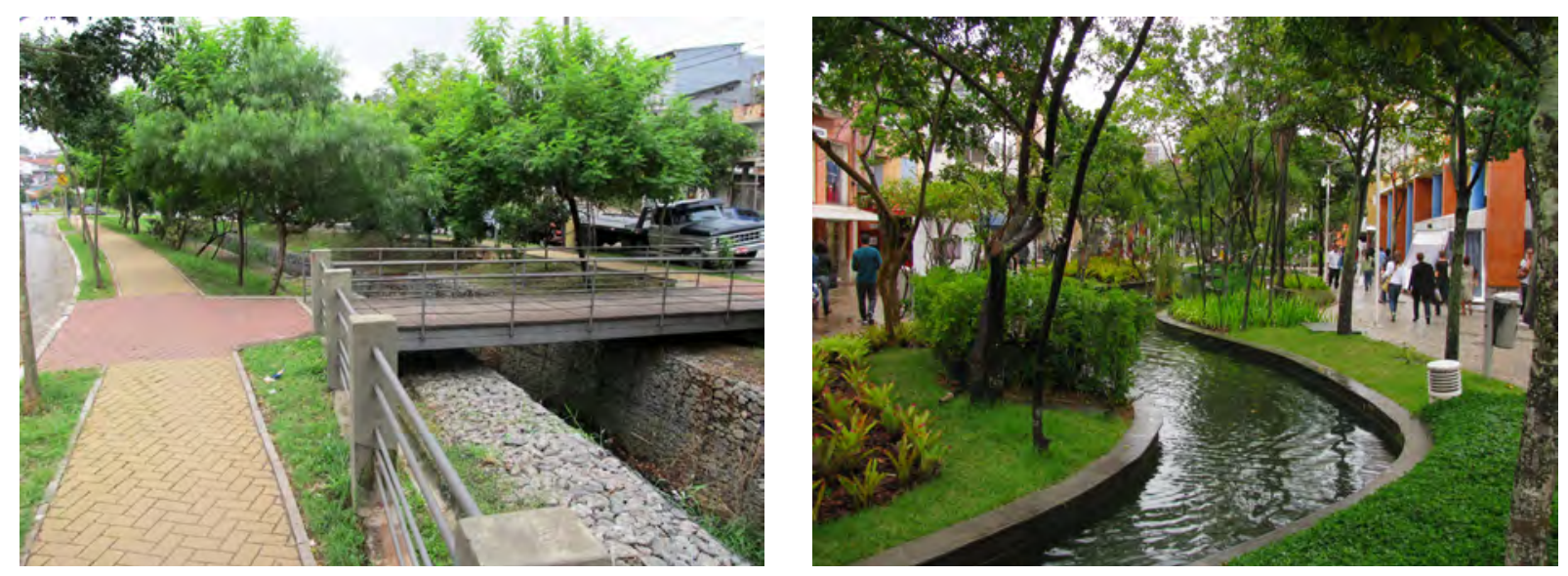

Figura 20: Parque Linear do Sapé. Fonte: visita no dia 15/05/2012. Figura 21: Shopping Downtown,

Barra da Tijuca, RJ. Fonte: visita em Maio/2011.

Também ocorre hoje um tipo de mimetismo às avessas nos espaços públicos: não é raro encontrarmos recentes projetos ditos de 'revitalização', como praças públicas, por exemplo, que imitam as ditas 'praças' dos shoppings (em particular, os materiais empregados, a paginação do piso e o cercamento), exatamente o contrário do ocorrido nas galerias e primeiros centros comerciais que mimetizavam os espaços públicos urbanos, as suas ruas e praças tradicionais. Hoje, paradoxalmente, a referência de espaço público dito 'de qualidade' passa a ser um espaço privado, na maior parte das vezes, um espaço interno, cercado e com segurança privada.

(JACQUES, p.164 apud ROSA, 2011).

Ainda com relação à produção dos parques lineares junto a corpos d'água, existe uma "brecha", em lei, comumente empregada pelo poder público municipal a seu favor. As canalizações de córregos com extensão inferior a $1 \mathrm{Km}$ são dispensados de licenciamento ambiental, EIA-RIMA ${ }^{16}$. Desta forma, é dada preferência à intervenção

15 JACQUES, Paola Berenstein. Microrresistências urbanas: por um urbanismo incorporado. In ROSA, Marcos. Microplanejamento. Práticas urbanas criativas. São Paulo, Editora Cultura, 2011.

16 Resolução n 61/CADES/2001. 
em córregos de menor extensão, relacionados a "pequenos parques lineares", que assemelham-se a praças, deixando de desempenhar muitas das funções inerentes a um parque linear, tanto na articulação e fortalecimento de manchas da matriz verde em meio à matriz cinza, quanto na melhoria da qualidade das águas urbanas. Esta manobra é ainda mais interessante ao poder público na medida em que multiplica-se o número de parques lineares implantados. O número de parques é explorado, portanto, como estratégia de marketing político. Os parques correm o risco de se resumirem a meros números, desconsiderando-se a importância de sua qualidade ambiental, social, humana, e sua relevância para as diversas escalas, desde o entorno imediato, à escala da bacia e da metrópole como um todo.

\section{SEGUNDA FASE}

A segunda fase de intervenção no Sapé, em processo de implantação, prevê o prolongamento do parque linear em meio à Favela do Sapé. Esta favela é composta por mais de 2.000 barracos, com uma estimativa populacional de 10.000 pessoas, de modo que a intervenção já tenha decorrido na remoção de 340 famílias e realocação de outras $430^{17}$. A população, autointitulada Comunidade do Sapé, está organizada em torno a reuniões e um blog, para disseminação e discussão dos novos acontecimentos.
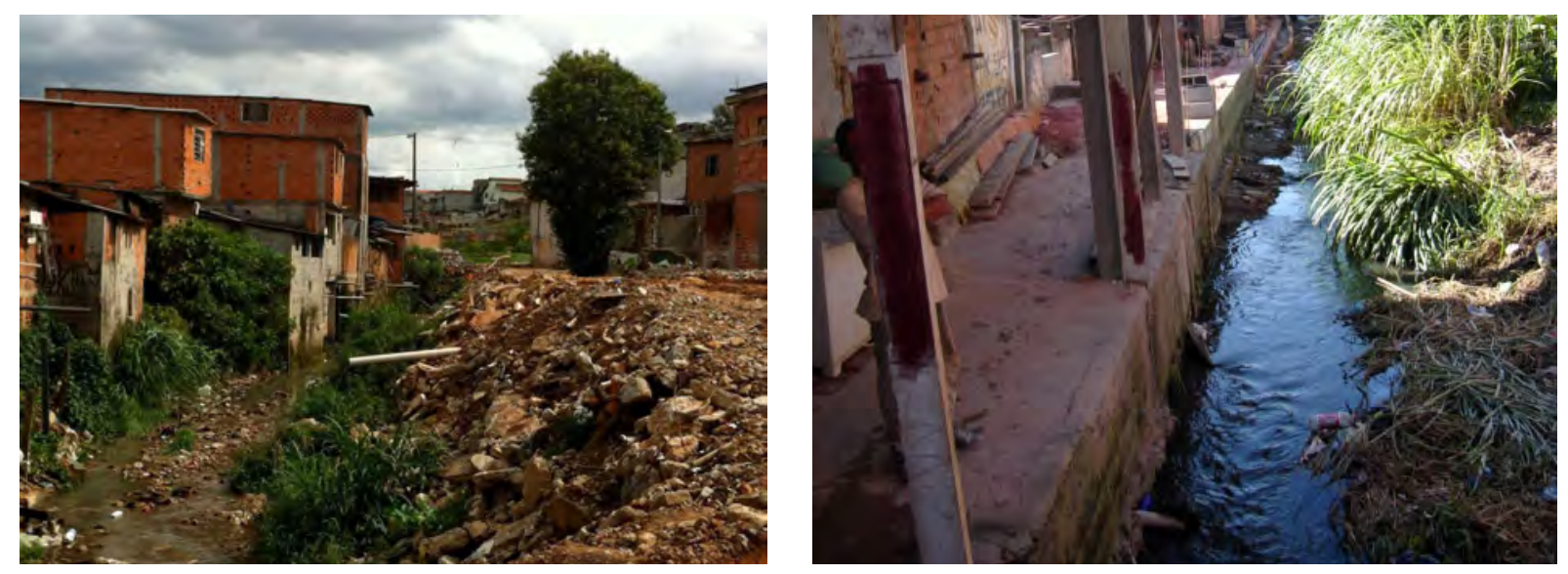

Figuras 22 e 23: situação do córrego antes do início das obras da $2^{\mathrm{a}}$ fase. Fonte: comunidadesape. blogspot.com.br.

17 Dados da Comunidade do Sapé: comunidadesape.blogspot.com. 

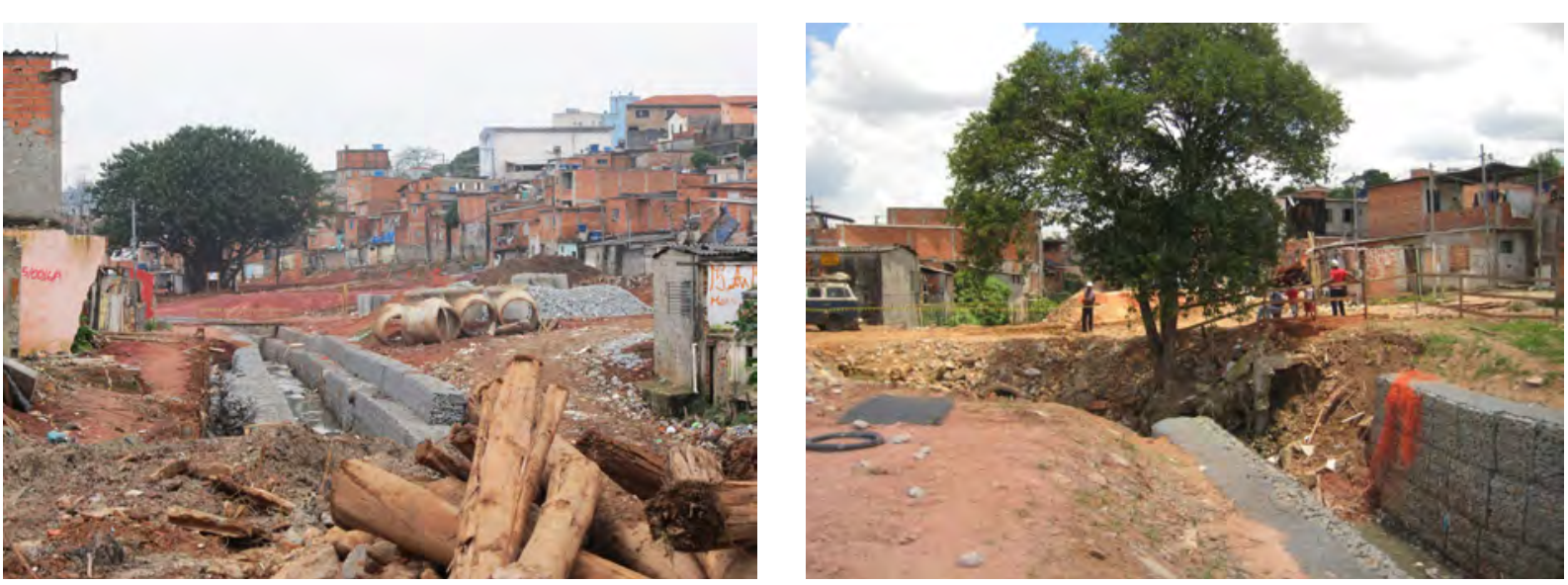

Figura 24: o processo de implantação da $2^{a}$ fase do parque. Fonte: visita no dia 15/05/2012. Figura 25: "árvore indo pelo ralo". Fonte: comunidadesape.blogspot.com.br.

A avaliação que se tem do parque é positiva. O parque é encarado como uma solução para as recorrentes enchentes. Uma moradora, Cristiane, relata: "Enfrentamos muitas enchentes. A cada chuva as pessoas ficam sem nada." ${ }^{18}$ A questão que ganha maior vulto entre os populares é a realocação de famílias e o aluguel social insuficiente.

\section{CONCLUSÃO}

A construção das cidades brasileiras e de suas infraestruturas, inclusive a verde, é resultado da sobreposição de diferentes compreensões, interesses e ações, por parte de atores públicos e privados, coletivos ou individuais. Apesar das diferenças, é comum a todos uma consciência fragmentada dos processos naturais e da relação estabelecida entre cidade e natureza e seu distanciamento de uma ação efetiva pautada pelos conceitos ecológicos. Neste ponto reside, de fato, o cerne do problema ambiental das grandes cidades brasileiras e, em especial, São Paulo.

Buscando-se um exemplo em outro parque municipal, em pesquisa ${ }^{19}$ elaborada pela administração do Parque Cidade de Toronto, em Pirituba, enquanto $100 \%$ dos entrevistados certificam a importância de se passar informações sobre a preservação do meio ambiente, $99,45 \%$ não gostaria de colaborar voluntariamente com o parque. As

$18 \quad$ www.comunidadedosape.blogspot.com.br.

19 Pesquisa realizada nos meses de Janeiro e Fevereiro de 2012, com 183 visitantes entrevistados. 
pessoas, hoje, sabem falar de algumas questões ambientais, superficialmente. Entretanto, não sabem como intervir efetiva e concretamente, de forma conjunta. $E$ isto não é exclusivo da população, é recorrente, também, nos âmbitos de intervenção público e privado.

Apesar de todas as críticas que se podem fazer em torno à intervenção pública na criação destes novos parques, este ator não deve ser, excessivamente, "diabolizado". Este setor, em diferentes medidas, em parceria com o poder privado e a população, está, no fundo, empenhado, ao menos tentando. Não deve, portanto, ser tirado seu mérito, porque este existe e muitos são os exemplos notáveis de bons projetos e manutenção de espaços livres na cidade.

Da mesma maneira, nós, arquitetos, urbanistas, paisagistas e pesquisadores, das antigas e novas gerações, não estamos fora desta lógica de reprodução do espaço urbano e devemos, portanto, assumir nossa parcela de "culpa". Mas é de nós, principalmente, que deve partir uma atitude questionadora, provocadora e propositiva. Vamos todos, então, tentar.

\section{REFERÊNCIAS}

BURDETT, Ricky. "Pensar a cidade para construir a cidade". In ROSA, Marcos L.. "Micro Planejamento. Práticas urbanas criativas". Editora Cultura, São Paulo, 2011;

FRANCO, Maria de Assunção Ribeiro. Desenho Ambiental - Introdução à Arquitetura da Paisagem com o Paradigma Ecológico. São Paulo, Annablume, 1997, 224 p;

FRANCO, Fernando de Mello. "Contrários e complementares." In ROSA, Marcos. Microplanejamento. Práticas urbanas criativas. São Paulo, Editora Cultura, 2011.

HOUGH, Michael. "Naturaleza y Ciudad. Planificación Urbana y Procesos Ecológicos". Barcelona, Gustavo Gili, 1998, 308 p;

JACQUES, Paola Berenstein. "Microrresistências urbanas: por um urbanismo incorporado". In ROSA, Marcos L.. "Micro Planejamento. Práticas urbanas criativas". Editora Cultura, São Paulo, 2011; 
LOTUFO, José Otávio. "Habitação social para a cidade sustentável". São Paulo, Dissertação de Mestrado, 2011, 155p.

ROGERS, Richard. "Cidades para um pequeno planeta". Barcelona, Editorial Gustavo Gili, 2001;

\section{Sites pesquisados}

www.prefeitura.sp.gov.br, acesso em 10/05/2012, às 21:30;

www.prefeitura.sp.gov.br/cidade/secretarias/meio_ambiente, acesso em 11/05/2012, às $15: 00$;

www.corregolimpo.com.br, acesso em 14/05/2012, às 14:30;

www.ibge.gov.br/censo2010/, acesso em 05/05/2012, às 9:30;

comunidadesape.blogspot.com, acesso em 15/05/2012, às 14:00; 